\title{
ACTIVE disPersal OF AN AQUATIC INVADER DETERMined BY RESOURCE AND FLOW CONDITIONS
}

\author{
ADAM SEPULVEDA $\uparrow$ USGS, NORTHERN ROCKY MOUNTAIN RESEARCH CENTER \\ LAURIE MARCZAK $\uparrow$ UNIVERSITY OF MONTANA $\uparrow$ MISSOULA
}

\begin{abstract}
$\uparrow \quad$ AbStract
New Zealand mudsnails (NZMS) have spread rapidly across the western United States, but little is known about mechanisms that drive their spread within invaded streams. We used a field experiment to test if upstream movement is a potential vector of NZMS spread and how this movement is modified by flow velocity and resource availability. We found movement direction and rates were related to flow velocity, while resource availability influenced the number of individuals that moved. In slow-flow treatments, individuals moved upstream at faster rates $(\sim 3 \mathrm{~m} / \mathrm{hr})$ than previously recorded for this species. In fast-flow treatments, most individuals were dislodged downstream and upstream movement rates were less than $2 \mathrm{~m} / \mathrm{hr}$. In low-resource treatments, individuals were more likely to move away from their initial starting locations. We suggest that upstream movement may be important in establishing new populations within local invasions and that increases in flow velocity may be an effective means to slow the upstream spread of NZMS. The surprisingly fast movements that we recorded predict greater distribution of NZMS within invaded streams than has actually occurred, which suggests that factors in addition to NZMS movement rate may limit population spread.
\end{abstract}

\section{$\downarrow \quad$ INTRODUCTION}

In the western United States, the expanding invasion of aquatic habitats by Potamopyrgus antipodarum, the New Zealand mudsnail (NZMS), is causing increasing levels of concern (Cowie et al. 2009; Davidson et al. 2008; Fromme, Dybdahl 2006; Levri et al. 2008; Loo et al. 2007; Richards et al.
2001; Riley et al. 2008). The NZMS provides little energy to consumers compared to native benthic macroinvertebrates and is capable of passing through the gut of fishes unharmed (Bruce et al. 2009; Cada 2004; Vinson, Baker 2008). With a high rate of clonal reproduction (Schreiber et al. 1998) and the ability to dominate invertebrate stream secondary production (Hall et al. 2003; Hall et al. 2006), NZMSs are poised to have effects on ecosystem function analogous to those of the zebra mussel (Hall et al. 2003).

While the NZMS has a long invasion history in Europe and Australia, its first recorded occurrence in North America is from the Snake River in Idaho in 1987 (Lysne, Koetsier 2006). It is now common in the Greater Yellowstone Ecosystem (GYE) and populations have been documented in all western US states except New Mexico (Benson 2008). NZMS have expanded the geographic extent of their invaded range largely through passive transport. Birds and fish have been suggested as passive dispersal mechanisms and passive drift or attachment to floating material have also been reported (Alonso, Castro-Diez 2008; Haynes et al. 1985; Richards et al. 2001). Fish stocking and the infestation of angling gear are frequently identified as sources of new populations (Bersine et al. 2008; Bruce et al. 2009; Cowie et al. 2009; Davidson et al. 2008).

In contrast, very little is known about mechanisms encouraging local dispersal once a population has established. Active, upstream movement is likely to be important in establishing new populations at the local scale but previous estimates of NZMS movement capabilities are largely anecdotal. In the GYE, Richards et al. (2001) observed that the movement rate of NZMS on flat substrate was $>1 \mathrm{~m} / \mathrm{hr}$; however, Adam (1942) found 
that NZMS in Belgium moved just $60 \mathrm{~m}$ over three months $(0.03 \mathrm{~m} / \mathrm{hr})$ of active upstream movement. Many freshwater invertebrates show active upstream movements, particularly snails (Huryn, Denny 1997), but movement rates vary. Large pulmonate snails (Physa sp.) can move as fast as $4.8 \mathrm{~m} / \mathrm{hr}$ (Hoffman et al. 2006), while the smaller stream-dwelling operculate snail, Elimia clavaeformis, moved no more than $5 \mathrm{~m} /$ day $(0.21 \mathrm{~m} / \mathrm{hr}$ ) (Burris et al. 1990). Hypotheses explaining deliberate upstream movements invoke the search for food or space, avoidance of predation and hydrodynamic effects. Additionally, decreased food resources are known to catalyze movement and many taxa exhibit densitydependent responses to resource levels in combination with physical habitat variation (Holomuzki, Biggs 2006a). Responses to variation in food resources may interact with other habitat parameters known to influence both dispersal rate and direction (Canepuccia et al. 2007; Elger et al. 2002; Elger, Lemoine 2005). For example, researchers have hypothesized that NZMS movement direction within streams is affected by flow rate (Holomuzki, Biggs 1999), but field studies have found conflicting results. Early investigators found that rates of spread in invaded streams were facilitated by a positive rheotactic response (Adam 1942; Haynes et al. 1985); higher water velocity produced more consistent upstream movement (Haynes et al. 1985). In direct contrast, Richards et al. (2001) found that NZMS are likely to detach from substrate at high flows $(0.34$ to $0.52 \mathrm{~m} / \mathrm{s})$, suggesting that faster flowing water may limit upstream colonization and potentially lead to the establishment of disjunct populations in downstream reaches.

The contradictory results of previous research indicate the need for detailed studies to understand the active upstream dispersal capabilities of this invasive snail under conditions of varying resource availability and flow. In this study, we used a manipulative field experiment to determine the ability for active upstream dispersal by NZMS and how this is modified by flow velocity and resource availability in a stream within the GYE. If flow velocity limits upstream dispersal, then we predict that upstream movements will be rare at faster flows. If resource availability drives upstream movement, then we predict that movement will increase as resources become scarce.

\section{Study organism and area}

New Zealand mudsnails were discovered in the GYE in 1994. Snails in these populations reach a maximum size of $6 \mathrm{~mm}$ and reach sexual maturity at
3 - $3.5 \mathrm{~mm}$ of shell length (Richards 2002). Populations in the GYE comprise only female individuals of a single clonal lineage (M.F. Dybdahl, unpublished data). Females are ovoviviparous and brood size can be up to 80 juvenile snails (all female). They are herbivorous and detritivorous scrapers.

We conducted our field experiments in Polecat Creek, a geothermal spring stream near the South Boundary area of Yellowstone Park that has been a focal area for NZMS research (see Hall et al. 2003 and Hall et al. 2006 for detailed site descriptions). Our site (UTM 12 524770E, $4884227 \mathrm{~N}$ ) was $400 \mathrm{~m}$ upstream of the Huckleberry Hot Springs outlet ( $2 \mathrm{~km}$ from Flagg Ranch) in the John D. Rockefeller National Parkway. Experiments occurred near base flow conditions on July $13-20^{\text {th }}$, 2010; stream temperature ranged from $17-21^{\circ} \mathrm{C}$ during this period.

\section{$\uparrow \quad$ METHODS}

\section{Esperimental design}

Movement experiments were conducted in three artificial arenas placed directly within the stream. Each arena consisted of a $600 \times 20 \mathrm{~cm}$ galvanized steel frame upon which 152 unglazed porcelain tiles $(5.08 \times 15.24 \mathrm{~cm})$ were arranged into 38 rows and 4 columns (Figure 1). The arenas received water directly from Polecat Creek.

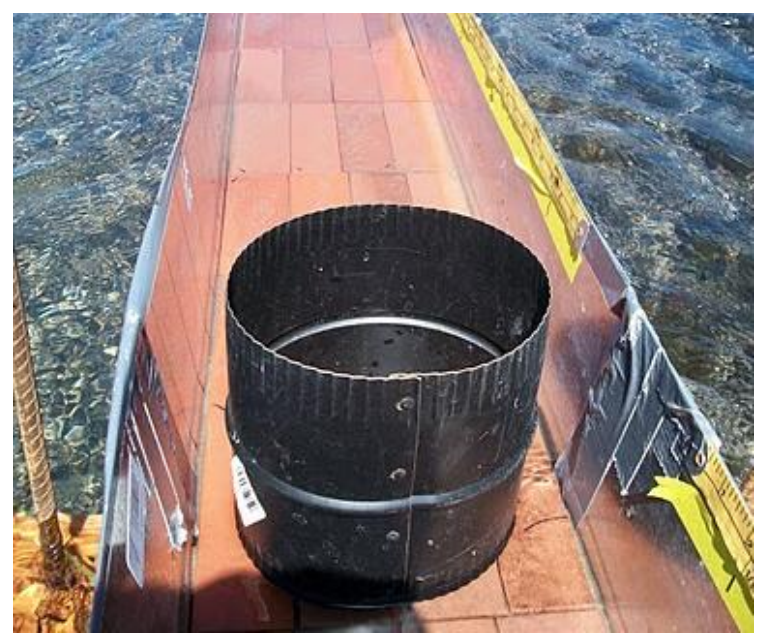

Figure 1. Photograph of the mid-point of an artificial arena used to conduct NZMS movement experiments. Tiles were arranged in 4 columns and 38 rows. A bottomless canister, placed at the mid-point of the arena, was used to acclimate NZMS to the arena (shown in the foreground). A measuring tape that spanned the length of the arena (shown on the right of the arena) was used to record NZMS movement distances. 
We used conditioned and unconditioned tiles to create three resource treatments: low, medium, and high. Conditioned tiles had been cultured in the stream adjacent to our arenas for 5 weeks prior to our experiments and had uniform, low-profile algal mats. Unconditioned tiles were not cultured in the stream and had no algal mats. Low resource treatments consisted of unconditioned tiles, medium resource treatments consisted of an equal number of conditioned and unconditioned tiles in a checkered arrangement, and high resource treatments consisted only of conditioned tiles.

We placed sandbags in front of each arena to create two flow velocity treatments: slow and fast. Sandbags were placed in front of the arena entrance to block flows (slow treatments) or to funnel flows (fast treatments). Slow treatments had flow velocities $<0.05 \mathrm{~m} / \mathrm{s}$ and fast treatments had flow velocities of $0.48-0.53 \mathrm{~m} / \mathrm{s}$. We measured flow immediately above the tiles at the upstream and downstream ends of each arena with a Swoffer Model 2100 current velocity meter (Swoffer Instruments, Inc. Seattle, WA). These velocities were within the range of velocities recorded near base flow conditions in 100$m$ reaches immediately upstream and downstream of our experiment (A.J. Sepulveda, unpublished data). In these reaches, flow velocities that exceeded 0.55 $\mathrm{m} / \mathrm{s}$ composed less than $2 \%$ of observed values these flows could not be used in our experiments because they mobilized the tiles.

We assessed the response of NZMS movement to all possible combinations of resource level and flow velocity treatments. Each combination was assigned randomly to an artificial arena and replicated eight times over eight days. Experimental animals were collected by hand in Polecat Creek and starved $12 \mathrm{~h}$ prior to performing a movement trial. To ensure that all individuals were large enough to be observed during movement trials, we used individuals that were $3.5-5.0 \mathrm{~mm}$ in length. Shell length was measured with calipers along the longest axis. Smaller individuals could not be observed consistently because they were able to move into the interstitial spaces between tiles. Thus, our experimental results only provide inferences about sexually mature adults.

Fifty experimental animals per trial were placed in a bottomless canister at the center of the experimental arena (Figure 1) and allowed to acclimate for 10 minutes. We initiated an experiment by removing the canister slowly and allowing individuals to move. During each trial, we recorded: (1) the maximum upstream and downstream movement distance of the farthest moving individuals, (2) the number of individuals on each tile row, (3) the number of individuals on conditioned vs. unconditioned tiles for the medium resource treatment, and (4) the size $(\mathrm{mm})$ of the individuals that moved the longest and shortest distances at the completion of the experiment. These data were recorded at 20-min intervals for a 120 -min period. Movement of experimental individuals was measured as distance from the arena center $(\mathrm{cm})$.

\section{Analysis of Movement}

To test if NZMS movement rate varied by resource level and flow velocity, we used the movement distances of the farthest moving individuals recorded at 20-min intervals for each 120min trial. We used the fastest downstream rate and the fastest upstream rate observed in each trial as response variables because it only takes one individual to establish a new population. For downstream movement rates, we used the position of the farthest moving individual regardless of how they moved to their current positions (i.e., active, crawling or passive, drifting). Because many individuals moved beyond the downstream boundary of our experimental reaches, maximum movement rates and distances were truncated. However, this was of little concern because our focus was on upstream movement. We used a random effects-mixed model to test for the response of movement rate to flow speed and resource level. Arena location was modeled as a random effect. Tukey honestly-significant-difference (HSD) post-hoc tests were used to assess significant differences among treatment levels. To ensure that maximum movement rates did not only occur at the beginning of each trial, we tested for correlation between maximum movement distance and time. To test if upstream movement rate was influenced by NZMS size, we used $t$-tests to compare the size of individuals that moved rapidly upstream against the size of individuals that did not move far from the origin of each arena.

To test if NZMS movement direction varied by resource level and flow velocity, we conducted tests of the general statistical properties of the movement distribution. We calculated movement distributions using histograms of the frequency of distances moved at the completion of each experiment (i.e., after 120 $\mathrm{min}$ ), arbitrarily assigning negative values to downstream moves and positive values to upstream moves. We assessed directional bias by testing for skewness of the movement distribution (Zar 1984). To compare the number of NZMS that moved downstream to those that moved upstream, we 
calculated the difference between the frequency of upstream and downstream movements. Positive values indicate that more individuals moved upstream than downstream while negative values indicate the opposite. We used a random effectsmixed model and Tukey HSD post-hoc tests to test if the difference between upstream and downstream movement varied by flow speed and resource level. We also used a random effects-mixed model and Tukey HSD post-hoc tests to test if the median distance of displacement by NZMS varied by flow speed and resource level. We used $t$-tests to test if the median distance of displacement was $>0 \mathrm{~cm}$ for each treatment combination.

To test if resource level influenced movement behavior, we used a random effects-mixed model and Tukey HSD post-hoc tests to compare the number of individuals on conditioned vs. unconditioned tiles in medium resource treatments. The hypothesis that resource quantity influences NZMS movement would be supported if individuals avoid unconditioned tiles.

To determine if NZMS movement could be characterized by simple diffusion, we tested the hypothesis that the variance of distance moved increased linearly with time (Skellam 1951, Turchin 1998). For this analysis, we regressed the estimated variance of distance moved on time $(0-120 \mathrm{~min}$ at 20-min intervals) using the polynomial equation $\mathrm{y}=\mathrm{c}_{\mathrm{o}}$ $+\mathrm{c}_{1} \mathrm{t}+\mathrm{c}_{2} \mathrm{t}_{2}$, where $y$ is the variance and $t$ is time. The hypothesis predicts $c_{o}=0, c_{1}>0$, and $c_{2}=0$. This analysis describes the spread of animals from a single release point. We also calculated the diffusion coefficient $(D)$ based only on upstream movement rates. If movement occurs by simple diffusion and there is a point release of individuals, as in our experiments, then $D$ can be estimated as MSD/4t, where MSD is the mean square displacement of released individuals at time $t$ (Kareiva 1983). We used a random effects-mixed model to test for the response of $D$ to flow speed and resource level. Arena location was modeled as a random effect. All analyses were completed using JMP 8.0.2 (SAS Institute Inc., Cary, NC).

\section{$\downarrow \quad$ PRELIMINARY RESULTS}

We found that NZMS can move upstream rapidly across all treatment combinations. Multiple individuals $(<5 \%)$ moved upstream and outside of our experimental arena (i.e., $>300 \mathrm{~cm}$ ). These individuals reached the upstream boundary of our arenas only during the last 20-minute observation period so the upstream tails of our movement distributions were minimally truncated and our estimates of movement rate were minimally biased to the first 100-minutes of each trial. The fastest upstream movement rate observed was $288 \mathrm{~cm} / \mathrm{hr}$. Individuals also moved downstream and beyond the experimental arena $(>300 \mathrm{~cm}$ ), especially in fast flows. However, more individuals moved upstream than downstream across all treatment combinations $\left(\chi^{2}=6.92, \mathrm{df}=1, P<0.01\right)$.

\section{Movement Rates}

Maximum upstream movement rates varied by flow velocity and resource level, but there was no interaction of flow $\times$ resource (Figure 2, Table 1). Individuals moved faster in slow flows than in fast flows and in low resource treatments than in high resource treatments. We found no difference in movement rates between low and medium resource treatments and medium and high resource treatments. Maximum movement rates were not correlated with time for any resource combination $(r<0.30$ for all tests). We also found no difference in size $(\mathrm{mm})$ between individuals that moved upstream at a fast rate and individuals that did not move far from the arena center ( $\mathrm{t}$-test: $\mathrm{t}=-1.15, \mathrm{df}=57, \mathrm{P}=0.26)$.

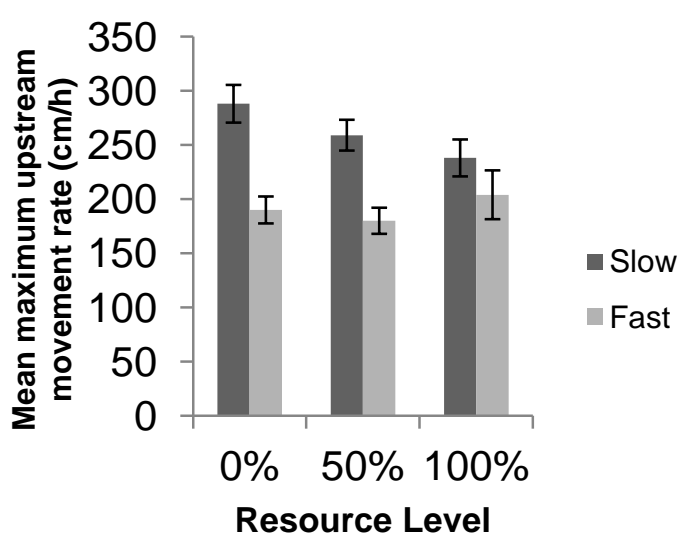

Figure 2. The mean maximum upstream movement rate $(\mathrm{cm} / \mathrm{h}, \pm 1 \mathrm{SE})$ observed for NZMS in each flow velocity and resource level combination. The maximum movement rate was estimated from 6, 20-minute observations per replicate.

Maximum downstream movement rates also varied by flow velocity and resource level, but we found no interaction of flow $\times$ resource $(\mathrm{F} 2,38=$ $0.56, \mathrm{P}=0.58)$. Individuals in fast flows moved downstream faster than individuals in slow flows $(\mathrm{F} 1,38=13.36, \mathrm{P}<0.01)$ and individuals in low resources moved downstream faster than individuals in medium and high resources $(\mathrm{F} 2,38=6.16, \mathrm{P}<$ $0.01)$. 
Table 1. Random designs mixed model table for (a.) the maximum upstream movement rate and (b.) the frequency of upstream movements of NZMS. Movement rates and direction were compared among flow velocity and resource level treatments. Arena was treated as a random factor nested within flow velocity.

\begin{tabular}{lrrr}
\hline Source & df & $\boldsymbol{F}$ & $\boldsymbol{P}$ \\
\multicolumn{3}{c}{ Max. upstream movement } \\
a. & & \\
Flow & 1 & 154.49 & $<0.01$ \\
Resource & 2 & 3.94 & 0.03 \\
Arena & 3 & 0.14 & 0.97 \\
Flow x Resource & 2 & 0.74 & 0.48 \\
& & & \\
Error & 38 & & \\
& & & \\
b. Frequency of upstream movement & \\
Flow & 1 & 80.91 & $<0.01$ \\
Resource & 2 & 8.95 & $<0.01$ \\
Arena & & 0.83 & 0.52 \\
Flow x Resource & 2 & 3.28 & 0.05 \\
Error & 38 & & $p$ \\
\hline Source & df & $F$ & \\
\hline
\end{tabular}

\section{Movement Direction}

The frequency distributions of distances moved was not upstream biased (i.e., skewness was not $>0)$ and skewness did not vary by flow or resource levels $(\mathrm{F} 8,39=0.76$ to $1.63, \mathrm{P}=0.15)$. However, the number of individuals that moved upstream v. downstream was biased and varied by flow and resource level (Figure 3, Table 1). More individuals moved upstream compared to downstream in slow flows, at medium and high resource levels. We also found a significant interaction of flow and resource. Populations in slow flows at medium and high resource levels had more individuals that moved upstream than populations in slow flows at low resource levels and populations at fast flows at all resource levels.

The median movement distances of each population were influenced by flow, but not by resource level (Figure 4). Populations in slow flows moved further upstream than populations in fast flows $(\mathrm{F} 1=11.58$, $\mathrm{P}<0.01)$. The median distance moved by populations in slow flows was $76.8 \mathrm{~cm} \pm 7 \mathrm{~cm}$ (1 SE) and significantly greater than 0 ( $\mathrm{t}$-test $=5.09$, df $=23, \mathrm{P}<$ $0.0001)$. The median distance in fast flows did not differ from $0 \mathrm{~cm}$ ( $\mathrm{t}$-test: $\mathrm{t} 23=0.79, \mathrm{P}=0.44$ ) because many individuals moved downstream.

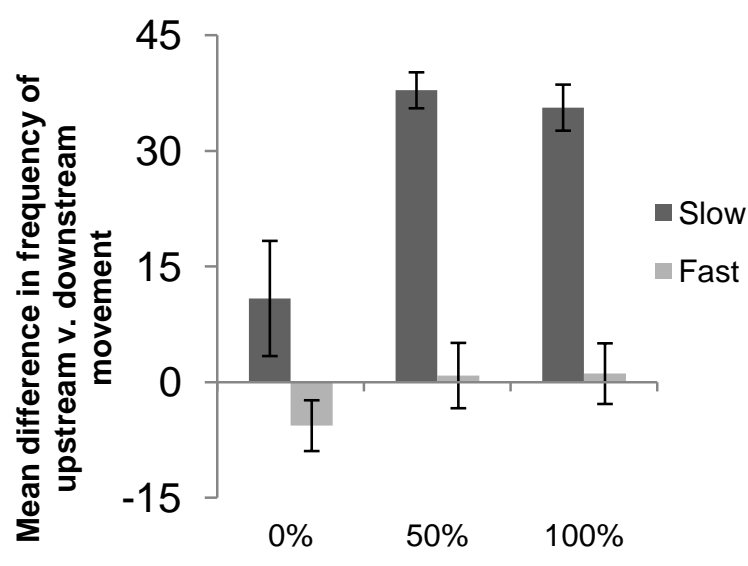

Resource Level

Figure 3. The mean difference ( $\pm 1 \mathrm{SE}$ ) in the number of individuals that moved upstream v. downstream. Positive numbers indicate that more individuals moved upstream, while negative numbers indicate that more individuals moved downstream.

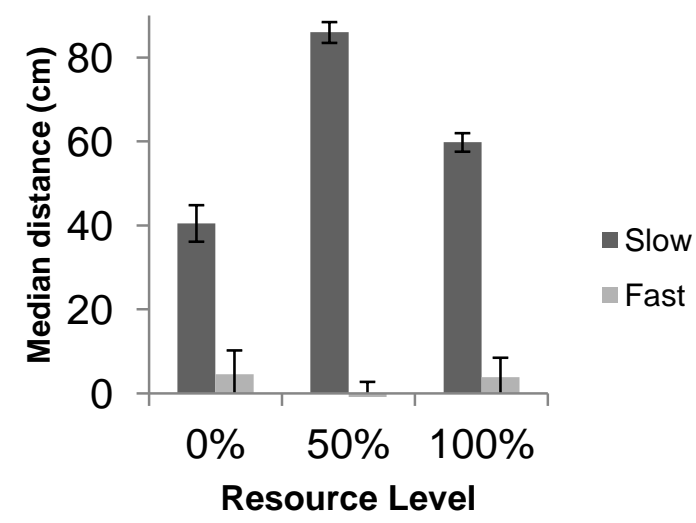

Figure 4. The median distance moved ( $\mathrm{cm}, \pm 1 \mathrm{SE})$ by populations of NZMS in each flow velocity and resource level combination.

In medium resource treatments, the median proportion of individuals on conditioned tiles was greater than the proportion of individuals on unconditioned tiles $(\mathrm{F} 1=1447.87, \mathrm{P}<0.01)$. Greater than $86 \%$ of observed NZMS were on conditioned tiles. NZMS in slow and fast flow velocities had a similar avoidance response to unconditioned tiles (F1 $=0.03, \mathrm{P}=0.87$ ).

\section{Diffusion}

NZMS movement in slow flows, across all resource levels, was consistent with a model of 
simple diffusion. Variance in distance moved increased linearly with time (linear regression for slow flow treatments across all resource levels: $F_{1,5}>$ $\left.100, P<0.005, r^{2}>0.96\right)$. The estimated intercepts of the variance in distance by time polynomial regressions did not differ from zero $(t=-0.93$ to $0.45, P>0.07)$, the slopes were significantly positive $(t>9.73, P<0.0001)$, and the quadratic terms did not differ from zero $(t=-0.98$. to $0.57, P>0.40)$. However, NZMS movement in fast flows, across all resource levels, did not fit a model of simple diffusion. Variance in distance moved did not increase linearly with time $\left(F_{1,5}<2.75, P>0.17, r^{2}<\right.$ $0.41)$. The estimated intercepts of the variance in distance by time polynomial regressions were not different from zero, the slopes did not all differ from zero, and the quadratic terms did not differ from zero.

The diffusion coefficient varied by flow velocity $\left(F_{9,38}=9.75, P<0.01\right) . D$ was greater in slow flows $\left(F_{1}=37.68, P<0.01\right)$, but did not differ significantly across resource levels $\left(F_{\mathrm{s}}=3.28, P=\right.$ $0.05)$. Populations in slow flows had a $D=18.66$ $\mathrm{m}^{2} /$ day $(15.36-21.96,95 \% \mathrm{CI})$, while individuals in fast flows had a $D=5.43(2.13-8.72,95 \% \mathrm{CI})$.

\section{$\uparrow \quad$ DISCUSSION}

Identifying the drivers of movement is essential for advancing a predictive theory about NZMS spread. We tested two variables that are known to influence movement in aquatic invertebrates: resource availability and flow velocity. Our results suggest that spatial variation in resource quantity is linked to NZMS movement behavior, but flow rate influences the direction and magnitude of movement. In our experimental channels, NZMS dispersed more rapidly away from the point of release in low resource treatments, whereas individuals in slow flow treatments moved upstream at rates three times faster than previously recorded. We suggest that upstream movement may be important in establishing new populations within local invasions and that increases in flow velocity may be an effective means to constrain the upstream spread of NZMS.

In theoretical models, temporal and spatial variation in habitat quality drive dispersal (Clobert 2001; Johnson, Gaines 1990; McPeek, Holt 1992). Temporal variation is critical to the initiation of dispersal, while spatial variation influences dispersal distance. Specifically, dispersal distance is predicted to increase when spatial variation in habitat quality is low because individuals must move farther to encounter higher-quality habitat (Lowe 2009). In our experiment, flow velocity is an analogue for temporal variation because flow varies seasonally while tile resource level represents spatial variation in habitat quality. Our results support the predicted relationship between spatial variation in habitat quality and distance moved, but do not support the predictions of temporal variation. We found that individuals moved regardless of flow speed and that movement distance and rate were greatest in low resource treatments. As spatial variability in habitat quality increased (i.e., medium resource treatments), movement rate and distance decreased. Alternative models of dispersal that emphasize inbreeding and kin competition as drivers (e.g., Perrin, Goudet 2001), rather than exogenous conditions, also do not explain our results. NZMS are clonal so inbreeding avoidance is not relevant and we found no evidence for food resource competition because movement initiation, rate, and distance did not vary between medium and high resource levels. Movement in low resource treatments was not related to resource competition because the tiles had no food resources. We suggest that future research focuses on intrapopulation variation in behavioral phenotypes (e.g., Fraser et al. 2001; Sih et al. 2004), where the propensity for individual movement is modified by the interaction of environmental and developmental conditions. Behaviors, such as boldness, have been linked to population heterogeneity in movement rates like we observed in NZMS (Fraser et al. 2001) and may explain why only a few individuals in each trial moved beyond the upstream boundary of our artificial arenas.

In addition to displaying heterogeneity in upstream movement rates, downstream movement rates of NZMS also varied among treatments. In slow flows with only low resource levels and in fast flows across all resource levels, individuals drifted passively downstream. Because these downstream movements occurred more frequently in slow flow / low resource treatments than in slow flow / medium resource and slow flow / high resource treatments, it is likely that individuals in slow flows actively detached from tiles and drifted downstream to search for patches of higher resource quality. In contrast, many individuals in fast flows were involuntarily dislodged from the experimental tiles and transported passively downstream. Alternatively, some individuals in fast flows may have actively detached from tiles because flow levels produced poor habitat quality. As a result, populations in fast flows did not meet the assumptions of simple diffusion because the distances of downstream movements were not consistent across time. 
The frequency distributions of movement distances were not skewed in an up- or downstream direction because the distances moved by active and passive downstream drift offset upstream movements across all treatments. However, we did find that movement direction was biased upstream in slow flow treatments and medium and high resource levels. At fast flows and low resource levels there was no bias because individuals passively and actively detached from tiles and drifted downstream. These results suggest that flow speed and food resources can limit the upstream spread of NZMS and increase the likelihood of disjunct downstream populations as observed by Richards (2002). Potential management strategies that may slow the upstream spread of NZMS include releases of high flows into invaded reaches downstream of dams. However, caution should be advised before using our results to inform management. Schreiber et al. (2003) found that fast flows can facilitate NZMS invasion because NZMS can recolonize denuded areas, which result from high flow events, faster than native stream invertebrates.

Hypotheses that may explain the upstream movement bias we observed include the search for food or space, avoidance of predation and hydrodynamic effects (Holomuzki, Biggs 2003, 2006b). We can reject the food hypothesis because we found that individuals were more likely to move downstream when food was limited in low resource conditions. There is also little prior evidence to support the predation hypothesis because native fish are ineffective consumers of NZMS (Vinson, Baker 2008) and fish occur upstream and downstream of NZMS in Polecat Creek and other invaded streams. However, upstream movement in response to predation pressure in downstream reaches may be a hardwired response acquired in the native habitat of NZMS, where fish and other organisms are effective consumers of NZMS. We cannot evaluate the hydrodynamic hypothesis because we did not measure shell polymorphisms along multiple axes. However, we measured lengths of $>2400$ snails and did not observe variation in shell morphology and found that movement direction and distance were not correlated with NZMS shell size measured along the longest axis. In addition, there is little evidence to support the hydrodynamic torque force hypothesis presented by Huryn and Denney (1997), which proposes that upstream movements by snails are a function of torque on the snail's foot generated by hydrodynamic drag on the shell. This hypothesis predicts that snails face and move upstream in order to reduce torque and stabilize orientation. In our experiments, we observed downstream orientation and movement in all treatments and we observed upstream movement even in low flow treatments that were below the threshold velocities for torque forces. In addition, our snails were all $<10 \mathrm{~mm}$ and the hydrodynamic torque force hypothesis suggests that torque only limits snails $>10 \mathrm{~mm}$.

Though movement distance was not upstream biased, we did find that NZMS have the potential to rapidly extend their range by moving upstream throughout invaded stream networks. Based on our movement rate estimates on homogeneous substrate (tile), NZMS should have the capacity to move through most watersheds within a few summers. This rapid rate of movement suggests a high probability of coming into contact with new vectors (e.g., humans, birds) that could extend the range of NZMS within an invaded watershed and transport them to an uninvaded watershed. However, we anticipate that the realized movement rate likely falls between our slow and fast flow velocity estimates because our artificial arenas had minimal roughness. Rougher substrate might aid movement in fast flows by providing refugia, but the topographic relief would decrease movement distance in both slow and fast flows. Interstitial space may also slow the potential movement rate of large snails $(>3.8 \mathrm{~mm})$, which have been found in the native range to be less active and spend more time below rocks during daylight hours than smaller individuals (Levri, Lively 1996). In our study, in which the majority of experimental individuals were $>3.8 \mathrm{~mm}$; we did not find that NZMS size was related to movement distance.

By comparing our experimental movement rates to the observed, temporal patterns of NZMS occurrence in the field, we can determine whether dispersal ability limits population spread. If the observed movement is much less than expected, then dispersal does not limit population spread and other factors (e.g., conductivity levels, phosphorus concentrations and flow disturbance; Herbst et al. 2008; Holomuzki, Biggs 2006b; Tibbets et al. 2009) restrict population movements to less than their maximum potential. If the observed and expected movement rates are similar, increasing flow velocity may be an effective means of slowing upstream NZMS spread. If the observed rate is greater than the expected rate, than passive dispersal mechanisms such as birds, fish, and humans may drive NZMS spread. In our study stream, NZMS were first observed in 1994 and currently occupy $<7 \mathrm{~km}$ of stream channel (R.O. Hall, University of Wyoming, personal communication). Even accounting for probable decreased movement rates on natural substrate, simple extrapolation from our experimental 
results predicts that NZMS had the potential to occupy the entire watershed by the present year (i.e., 16 years). In this stream, factors other than dispersal ability are likely combining to limit population spread. We suggest that our estimates of NZMS movement rate and the coefficient of diffusion $(D)$ can be used as tools to determine whether dispersal is limiting (and thus flow controls might be useful) or whether other physical and biotic factors are more effective in controlling NZMS spread in any given invaded watershed.

\section{$\uparrow \quad$ CONCLUSIONS}

Developing measures to slow the spread of invasive species can be easier and more effective than controlling established populations (Sakai et al. 2001; Sharov, Liebhold 1998). But to slow the spread of invasive species, managers need knowledge about their movement behavior. In this study, we used a field experiment to advance understanding of NZMS movement rate and direction. We found that NZMS moved upstream at faster rates than previously recorded, especially in low-gradient conditions. We suggest that upstream movement may be important in establishing new populations and that increases in flow velocity may be an effective means to slow the upstream spread of NZMS. The surprisingly fast movements that we recorded suggest that other factors in addition to NZMS movement rate limit population spread at our study stream because the observed colonization rate was much lower than our experimental estimates of movement capability would predict. Future research should focus on identifying the physical and biotic characteristics of streams that limit population spread.

\section{$\uparrow \quad$ Literature Cited}

Adam W. 1942. Sur la repartition et la biologie de Hydrobia jenkinsi (Smith) en Belgique Bulletin de Musee Royal d'Histoire Naturell de Belgique 18:1-18.

Alonso A, Castro-Diez P. 2008. What explains the invading success of the aquatic mud snail Potamopyrgus antipodarum (Hydrobiidae, Mollusca)? Hydrobiologia 614:107-116.

Benson AJ. 2008. New Zealand mudsnail sightings distribution. Center for Invasive Species Research, retrieved March 5, 2010 from newzealandmudsnaildistribution.aspx.
Bersine K, Brenneis VEF, Draheim RC, et al. 2008 Distribution of the invasive New Zealand mudsnail (Potamopyrgus antipodarum) in the Columbia River Estuary and its first recorded occurrence in the diet of juvenile Chinook salmon (Oncorhynchus tshawytscha). Biological Invasions 10:13811388.

Bruce RL, Moffitt CM, Dennis B. 2009. Survival and passage of ingested New Zealand mudsnails through the intestinal tract of rainbow trout. North American Journal Of Aquaculture 71:287-301.

Burris J, Bamford M, Stewart A. 1990. Behavioral responses of marked snails as indicators of water quality. Environmental Toxicology and Chemistry 9:69-76.

Cada C. 2004. Interactions between the invasive New Zealand Mud Snail, Potamopyrgus antipodarum, baetid mayflies, and fish predators. Biological Sciences. Montana State University, Bozeman, Montana, pp. 135.

Canepuccia AD, Escapa M, Daleo P, et al. 2007 Positive interactions of the smooth cordgrass Spartina alterniflora on the mud snail Heleobia australis, in South Western Atlantic salt marshes. Journal Of Experimental Marine Biology And Ecology 353:180-190.

Clobert J. 2001. Dispersal. Oxford University Press, USA.

Cowie RH, Dillon RT, Robinson DG, et al. 2009. Alien non-marine snails and slugs of priority quarantine importance in the United States: A preliminary risk assessment. American Malacological Bulletin 27:113-132.

Davidson TM, Brenneis VEF, de Rivera C, et al. 2008. Northern range expansion and coastal occurrences of the New Zealand mud snail Potamopyrgus antipodarum (Gray, 1843) in the northeast Pacific. Aquatic Invasions 3:349-353.

Elger A, Barrat-Segretain MH, Amoros C. 2002. Plant palatability and disturbance level in aquatic habitats: an experimental approach using the snail Lymnaea stagnalis (L.). Freshwater Biology 47:931-940. 
Elger A, Lemoine D. 2005. Determinants of macrophyte palatability to the pond snail Lymnaea stagnalis. Freshwater Biology 50:86-95.

Fraser D, Gilliam J, Daley M, et al. 2001 Explaining leptokurtic movement distributions: intrapopulation variation in boldness and exploration. American Naturalist 158:124135.

Fromme AE, Dybdahl MF. 2006. Resistance in introduced populations of a freshwater snail to native range parasites. Journal Of Evolutionary Biology 19:1948-1955.

Hall R, Tank JL, Dybdahl MF. 2003. Exotic snails dominate nitrogen and carbon cycling in a highly productive stream. Frontiers In Ecology And The Environment 1:407-411.

Hall RO, Dybdahl MF, VanderLoop MC. 2006. Extremely high secondary production of introduced snails in rivers. Ecological Applications 16:1121-1131.

Haynes A, Taylor B, Varley ME. 1985. The influence of the mobility of Potamopyrgus jenkinsi (Smith EA) (Prosobranchia: Hydrobiidae) on its spread. Archiv fur Hydrobiologie 103:497-508.

Herbst D, Bogan M, Lusardi R. 2008. Low specific conductivity limits growth and survival of the New Zealand mud snail from the Upper Owens River, California. Western North American Naturalist 68:324-333.

Hoffman A, Olden J, Monroe J, et al. 2006. Current velocity and habitat patchiness shape stream herbivore movement. Oikos 115:358-368.

Holomuzki J, Biggs B. 1999. Distributional responses to flow disturbance by a stream-dwelling snail. Oikos 87:36-47.

Holomuzki J, Biggs B. 2003. Sediment texture mediates high-flow effects on lotic macroinvertebrates. Journal of the North American Benthological Society 22:542553.

Holomuzki J, Biggs B. 2006a. Food limitation affects algivory and grazer performance for New Zealand stream macroinvertebrates. Hydrobiologia 561:83-94.
Holomuzki J, Biggs B. 2006b. Habitat-specific variation and performance trade-offs in shell armature of New Zealand mudsnails. Ecology 87:1038-1047.

Huryn A, Denny M. 1997. A biomechanical hypothesis explaining upstream movements by the freshwater snail Elimia. Functional Ecology 11:472-483.

Johnson M, Gaines M. 1990. Evolution of dispersal: theoretical models and empirical tests using birds and mammals. Annual review of Ecology and Systematics:449-480.

Kareiva P, Shigesada N. 1983. Analyzing insect movement as a correlated random walk. Oecologia 56:234-238

Levri E, Lively C. 1996. The effects of size, reproductive condition, and parasitism on foraging behaviour in a freshwater snail, Potamopyrgus antipodarum. Animal Behaviour 51:891-901.

Levri EP, Jacoby WJ, Lunnen SJ, et al. 2008. The invasive New Zealand mud snail in the Great Lakes region. Journal of the Pennsylvania Academy of Science 81:125.

Loo SE, Mac Nally R, Lake PS. 2007. Forecasting New Zealand mudsnail invasion range: Model comparisons using native and invaded ranges. Ecological Applications 17:181-189.

Lowe W. 2009. What drives long-distance dispersal? A test of theoretical predictions. Ecology 90:1456-1462.

Lysne S, Koetsier P. 2006. Experimental studies on habitat preference and tolerances of three species of snails from the Snake River of southern Idaho, USA. American Malacological Bulletin 21:77-85.

McPeek M, Holt R. 1992. The evolution of dispersal in spatially and temporally varying environments. American Naturalist 140:1010-1027.

Perrin N, Goudet J. 2001. Inbreeding, kinship, and the evolution of natal dispersal. Oxford University Press. 
Richards D. 2002. The New Zealand mudsnail invades the western United States. Aquatic Nuisance Species Digest 4:42-44.

Richards D, Cazier L, Lester G. 2001. Spatial distribution of three snail species, including the invader Potamopyrgus antipodarum, in a freshwater spring. Western North American Naturalist 61:375-380.

Riley LA, Dybdahl MF, Hall RO. 2008. Invasive species impact: asymmetric interactions between invasive and endemic freshwater snails. Journal of The North American Benthological Society 27:509-520.

Sakai A, Allendorf F, Holt J, et al. 2001. The Population Biology of Invasive Species. Annual review of Ecology and Systematics:305-332.

Schreiber E, Quinn G, Lake P. 2003. Distribution of an alien aquatic snail in relation to flow variability, human activities and water quality. Freshwater Biology 48:951-961. Schreiber ESG, Glaister A, Quinn GP, et al. 1998. Life history and population dynamics of the exotic snail Potamopyrgus antipodarum (Prosobranchia: Hydrobiidae) in Lake Purrumbete, Victoria, Australia. Marine and Freshwater Research 49:73-78.
Sharov A, Liebhold A. 1998. Model of slowing the spread of gypsy moth (Lepidoptera: Lymantriidae) with a barrier zone. Ecological Applications 8:1170-1179.

Sih A, Bell A, Johnson J. 2004. Behavioral syndromes: an ecological and evolutionary overview. Trends in Ecology \& Evolution 19:372-378.

Skellam J. 1951. Random dispersal in theoretical populations. Biometrika 38:196-218.

Turchin P. 1998. Quantitative analysis of movement: measuring and modeling population redistribution in animals and plants. Sinauer Associates, Sunderland, Massachusetts, USA.

Tibbets T, Krist A, Hall R, et al. 2009. Phosphorusmediated changes in life history traits of the invasive New Zealand mudsnail (Potamopyrgus antipodarum). Oecologia:111.

Vinson M, Baker M. 2008. Poor growth of rainbow trout fed New Zealand mud snails Potamopyrgus antipodarum. North American Journal of Fisheries Management 28:701-709.

Zar J. 1984. Biostatistical analysis. 2nd. Edition. Englewood Cliffs: New Jersey. 